\title{
Prevalence of Opioid Abuse in Interventional Pain Medicine Practice Settings: A Randomized Clinical Evaluation
}

\author{
Laxmaiah Manchikanti, MD*, Vidyasagar Pampati, MSc ${ }^{\star *}$, Kim S. Damron, RN"\#, Bert Fellows, MA, \\ Renee C. Barnhill, RN"\#, and Carla Beyer, RN\#\#
}

While drug therapy is one of the most commonly used modalities of treatment in managing persistent or chronic pain, controversy continues with regards to the appropriate use of controlled substances, specifically opioid analgesics, in interventional pain medicine settings.

This study included 100 randomly selected patients receiving opioids in an interventional pain medicine setting. The patient's controlled substance profile was evaluated using multiple means. The patients were divided into two groups, with 76 patients in the non-abuse group and 24 patients in the abuse group after data collection. There were no significant differences noted either in demographic characteristics or psychological characteristics, except for a higher

Drug therapy is one of the most commonly used modalities of treatment in managing persistent or chronic pain. However, controversy continues with regards to use of controlled substances, specifically opioid analgesics, in managing chronic or recurrent pain. The fear of addiction from using opioids for chronic pain goes back to the early 1800 s when Coleridge and deQuincey took opium for "internal rheumatism" and "stomachache" (1). Opioids have long been accepted as appropriate for the management of acute and cancer pain. However, physicians and health care professionals are reluctant to support the use of opioid medication for patients with chronic pain because of concerns they have about efficacy, adverse effects, tolerance, and addiction (2-4). Yet $40 \%$ to $90 \%$ of patients in pain treatment facilities receive controlled drugs, specifically opioids (5-7). We live in a drug oriented society with a high prevalence of substance abuse. As early as 1992, it was shown that $33 \%$ of the population of the United States

From Pain Management Center of Paducah, Paducah, Kentucky. *Medical Director, **statistician, ${ }^{*}$ clinical coordinators, and ${ }^{\Omega}$ psychologist at the Pain Management Center of Paducah. Address correspondence: Laxmaiah Manchikanti, MD, 2831 Lone Oak Road, Paducah, Kentucky 42003. E-mail: drm@asipp.org prevalence of depression in the abuse group.

In conclusion, there was significant abuse of opioids in an interventional pain medicine setting, with an incidence of $24 \%$, with frequent abuse seen in almost half of these patients. Thus, it is important for interventional pain physicians to recognize this possibility and also to recognize that there is no definite physiologic, psychologic or demographic information to suggest abuse, even though depression was more prevalent in abuse patients.

Keywords: Opioids, chronic pain, physical dependency, psychological dependency, drug addiction, drug abuse, controlled substance contract

sampled illicit drugs (8), and as many as $15 \%$ had a substance use disorder of some type (9). Fishbain et al (10), studying drug abuse and dependency in chronic pain patients, concluded that between $3.2 \%$ and $18.9 \%$ of patients have been diagnosed with a substance abuse disorder. Polatin et al (11) showed current substance abuse of $19 \%$ and lifetime prevalence of $36 \%$ in chronic low back pain. Thus, diagnosis and management of patients with drug abuse is not only challenging, but also extremely difficult. It is compounded by ongoing criticism of the medical profession for undertreatment of chronic pain, and lack of conclusive evidence that controlled substances' improve the quality of life.

Some randomized, controlled studies have supported the efficacy of opioid treatment of patients with chronic pain (12-14). While these trials suggest that opioids can improve the level of analgesia and quality of life in some patients, other studies suggest that some patients become psychologically dependent after long-term opioid use (15); whereas other investigators believe that opioid analgesics contribute to psychological distress, poor treatment outcome, impaired cognition and a fostered reliance on the health care system (16-20). Many physicians who prescribe opioids for chronic noncancer pain worry not only about possible abuse by patients, but also about potential 
liability and censure by regulatory agencies $(2,4,21,22)$. Considering the controversy, Wilson (23) noted, "There appears to be little hope for a rational outcome as the discussion is dominated by zealots at one extreme and nihilists at the other." The recent initiatives by the Joint Commission on Accreditation of Healthcare Organizations (JCAHO) and numerous recent reports of abuse of OxyContin ${ }^{\circledR}$ have once again sparked the heated debate about various issues involving controlled substances. A consensus statement was released by the American Academy of Pain Medicine and the American Pain Society on the use of opioids for the treatment of chronic pain. Opioid use at times has been described as pseudoaddiction, undertreatment or pseudolabeling.

New pain management standards for American healthcare institutions took effect in 2001, developed by JCAHO, understandably with implications for interventional pain specialists. These new regulations target often-woeful mismanagement of pain among various groups of patients presenting to healthcare institutions. The JCAHO believes that, "Unrelieved pain has enormous physiological and psychological effects on patients. Effective management of pain is a crucial component of good care." The JCAHO also asserts that, "Research clearly shows that unrelieved pain can slow recovery, create burdens for patients and their families, and increase costs to the healthcare system," even though, JCAHO has failed to present any such evidence. Further, patient advocacy groups find that a majority of pain sufferers are dissatisfied with their pain relief medications. While JCAHO's new standards for the treatment of pain appear to be an ideal to be endorsed and welcomed with open arms by all professionals, especially professionals in pain medicine, the reality is much more complex. It is quite possible that this well-intended standard may lead to overuse of controlled analgesics. Even though there are many other methods of managing pain productively, narcotics are used either as a first option or in conjunction with other modalities of treatments. Controlled substance overuse is a major concern in general and specifically among the elderly, with widespread reports of OxyContin $®$ abuse.

In addition, regulatory policies also negatively affect physician prescribing and lead occasionally to undertreatment. Even though regulation of controlled drugs is not intended to impede legitimate prescribing for appropriate medical purposes, the impact of controlled substance therapy, specifically opioid therapy, on the physical and psychosocial functioning of patients with chronic nonmalignant pain continues to be a contentious issue for pain specialists.
Therapy for chronic or persistent pain is usually guided by the dual goals of comfort and function. Thus, opioid therapy would not be useful if it augmented disability or undermined the efficacy of rehabilitation efforts, regardless of its effects on the pain. The evidence in favor of heavy narcotic management is inconclusive. In addition, abuse of opioids and other adjuvant agents utilized in pain treatment programs, including the drugs for managing anxiety, has been claimed to be extremely low. However, it has not been studied in interventional pain medicine settings. Since opioid abuse is considered a significant problem by some authorities, this study was undertaken to evaluate the abuse of opioids in an interventional pain medicine setting.

\section{METHODS}

One hundred patients from an active group of patients treated at an interventional pain medicine setting with or without interventional techniques, but receiving controlled substances, specifically opioids, were randomly selected by computer allocation from a patient pool of 2,685. There were no specific exclusion criteria. Following the initial selection, charts of all patients were reviewed, with special attention to the present drug treatment, and the patient history with regards to the drugs they have been taking from outside the organization. All patients had signed controlled substance contracts in the chart. The data collection was multifaceted: data collection was from pharmacy records, chart review, and the information from all physicians involved in the treatment of the patient, and agreed to by the patient in their controlled substance contract.

Frequent abuse was defined as the occurrence of obtaining a prescription (of a minimum of at least 30 tablets) of a controlled substance at least once a month from another physician without approval of the pain physician signing the controlled substance contract. Acquiring drugs for emergency purposes was not considered an abuse.

Data were collected using a preprinted format with demographic information and drug history and was compared with all the acquired information.

Data were recorded on a database using Microsoft $\AA$ Access ${ }^{\circledR}$. The SPSS version 9.0 statistical packages were used to generate the frequency tables and chi-squared statistic was used to test the significant difference between genders. Fisher's exact test was used wherever expected value was less than 5 . Student's t-test was used to test mean significant difference between groups. Results were 
considered statistically significant if the $P$ value was less than 0.05 .

\section{RESULTS}

Data were evaluated for patient characteristics, prevalence of abuse of opioids in an interventional pain medicine setting, and frequency of abuse of controlled substances.

\section{Patient Characteristics}

Demographic data are shown in Table 1, with no significant differences noted between the two groups, Group I being the nonabuse group, and Group II being the abuse group. There were 76 patients in Group I and 24 patients in Group II, with no significant differences noted between these groups in terms of gender, age, weight, height, mode of onset of pain and duration of pain. In addition, there was no significant difference noted in number of regions involved. Overall, previous surgery was also similar in both groups. Referral patterns were also similar, with $42 \%$ of the patients in Group I and 33\% of the patients in Group II having self-referral.

\section{Psychological Status}

As shown in Table 2, psychological status was evaluated in all 100 patients. Depression was most commonly seen, with $45 \%$ of the patients presenting with depression in Group I and $75 \%$ of patients presenting with depression in Group II, which was significantly higher in the abuse group. Generalized anxiety disorder was the next most common phenomenon, with $41 \%$ of the patients suffering with this disorder in Group I and $46 \%$ in Group II. Similarly, somatization disorder was also present in $13 \%$ of the patients in Group I and 17\% in Group II.

\section{Nonphysiological Signs and Symptoms}

Nonphysiological symptoms as described by Waddell were present in 9\% of the patients in Group I and 17\% in Group II, with no significant differences noted between the groups.

Table 1. Patient demographic characteristics

\begin{tabular}{llcc}
\hline & & $\begin{array}{c}\text { Group I } \\
\text { Nonabuse group } \\
\text { N = 76 }\end{array}$ & $\begin{array}{c}\text { Group II } \\
\text { Abuse group } \\
\text { N = 24 }\end{array}$ \\
\hline \multirow{2}{*}{ Age (yrs.) } & Male & $32 \%(24)$ & $46 \%(11)$ \\
\hline Weight (lbs.) & Female & $68 \%(52)$ & $54 \%(13)$ \\
\hline Height (inches) & $<65$ & $83 \%(54)$ & $96 \%(23)$ \\
\cline { 2 - 4 } & $>65$ & $17 \%(11)$ & $4 \%(1)$ \\
\hline \multirow{2}{*}{ Mode of onset of pain } & Mean + SEM & $163.5+4.57$ & $176.7+10.98$ \\
\hline Duration of pain (months) & Mean + SEM & $66.0+0.42$ & $66.6+0.58$ \\
\hline \multirow{2}{*}{ Number of regions involved } & Occupational & $20 \%(15)$ & $38 \%(9)$ \\
& MVA & $14 \%(11)$ & $4 \%(1)$ \\
\hline Previous surgery & Nonoccupational & $13 \%(10)$ & $25 \%(6)$ \\
\hline Referral & Gradual onset & $53 \%(40)$ & $33 \%(8)$ \\
\hline & Mean + SEM & $149+17.2$ & $139+22.1$ \\
\hline
\end{tabular}


Table 2. Psychological characteristics

\begin{tabular}{llcc}
\hline & & $\begin{array}{c}\text { Group I } \\
\text { Nonabuse group } \\
\text { N = 76 }\end{array}$ & $\begin{array}{c}\text { Group II } \\
\text { Abuse group } \\
\mathbf{N}=\mathbf{2 4}\end{array}$ \\
\hline & & Depression & $75 \% *(18)$ \\
Psychological status & Generalized anxiety disorder & $41 \%(31)$ & $46 \%(11)$ \\
& Somatization & $13 \%(10)$ & $17 \%(4)$ \\
\hline Presence of nonphysiologic symptoms & & $9 \%(7)$ & $17 \%(4)$ \\
Presence of nonphysiologic signs & & $9 \%(7)$ & $4 \%(1)$ \\
Presence of symptom magnification & & $11 \%(8)$ & $17 \%(4)$ \\
\hline $\begin{array}{l}\text { Total numbers do not match, as many patients were positive for more than one condition. } \\
\text { *Denotes significant difference }\end{array}$ & &
\end{tabular}

There were also no significant differences noted with regards to the presence of nonphysiologic signs, which were present in $9 \%$ of the patients in Group I and 4\% in Group II. Symptom magnification was present in $11 \%$ of the patients in Group I and 17\% in Group II.

\section{Abuse Pattern}

Frequent abuse, defined as opioid abuse at least once a month, involving at least one prescription of 30 tablets, was seen in $12 \%$ of total sample or $50 \%$ of abuse group.

\section{DISCUSSION}

The literature is replete with reviews, editorials and opinion papers regarding the chronic use of not only opioids, but also other controlled substances for the management of chronic pain. Physicians are also bombarded with fears of losing their license on one side, unreliability of patients on another side, news from advocacy organizations on still another side, and also from patients and drug enforcement agencies. Even though there are numerous guidelines and outlines for prescribing controlled substances, and many proponents of narcotic use in chronic pain continue to profess the low incidence of abuse, substance abuse in chronic low back pain patients has been described as being $19 \%$ at the time of evaluation and $36 \%$ over a lifetime (24). Thus, contracts are widely used in the chronic administration of potentially abusable substances or the management of lethal behaviors (25); however, the efficacy of contractual agreements between physician and patient is not well established. Fishman et al (25) reviewed opioid contracts from 39 major academic pain centers and analyzed every statement for its core meaning, grouping them into general categories and then into specific statement groups. They concluded that, while there were many significant issues related to the usage of a formal contract in chronic opioid therapy, there was substantial consistency among the contracts in their universal attempts to improve care through dissemination of information, to facilitate mutually agreedupon codes, or to enhance compliance. However, there are no studies in the literature evaluating the abuse of controlled substances or deviation from a controlled substance contract, specifically in an interventional pain medicine setting. Thus, the role of opioids and other controlled substances in the management of chronic pain continues to be hotly debated within the medical, ethical, and regulatory communities.

From the 1880 s to immediately after World War I, many outside the medical profession, and several within the medical profession, held physicians largely responsible for the serious addiction problems sweeping the United States, not only with opioids, but also various other substances. To control the problem, Congress passed a law in 1914 that placed responsibility for narcotics control in the hands of the Bureau of Internal Revenue, which in turn set up a field force to carry out day-to-day investigations (26). By the end of the 1920s, these heavy-handed tactics had taken their toll, and physicians became extremely leery of prescribing narcotics. They were also fearful of addiction. By the mid 1980s, physician fear hit new levels as politicians eager to show their mettle vied with one another to pass tougher and tougher drug laws. The effects of the crackdown, though probably unintended, were nevertheless severe, narrowing the scope of medical practice with these drugs. Beginning in the 1990s, rigid attitudes toward the use of narcotics to control pain began to relax, 
both within the medical community and outside it. However, the trend, experts say, has reversed again in the late 90s and early 2000s. In favor of liberal use of narcotics, there has been a growing body of literature showing that, contrary to long-standing myth, intractable pain patients who have been properly treated with opioids rarely become addicted; however, this only applied to acute and cancer pain. During this time, some proponents of narcotics and chronic pain have renamed addiction as pseudoaddiction and undertreatment. However, abuse also has been regularly increasing in parallel with patient advocacy groups and proponents of narcotic use in chronic pain.

In general, physicians and pain specialists have been blamed for undertreating pain whether it is acute pain, chronic pain or cancer pain (27). The fear of opioid use has been described as opiophobia, which by the proponents has been described as resulting from lack of information among physicians about the value and use of opioids as pain relievers and the true nature of addiction. Further, long-running anti-drug campaigns by state and federal governments have contributed to misinformation about what behavior constitutes true addiction, according to experts supporting liberal narcotic or opioid use for chronic pain. The literature also shows that narcotic prescription usage, along with abuse, has increased substantially in the 1990s.

As a result of increased use of controlled substances, many state medical boards have released guidelines or position statements (28-31), and electronic reporting of scheduled substances (32). Excerpts from one such report (28) from model guidelines for the use of controlled substances in pain treatment are:

- Pain management is particularly important for patients who experience pain as a result of terminal illness and can be difficult for patients with chronic nonterminal pain. It is imperative that physicians become knowledgeable about effective methods of pain treatment as well as statutory requirements for prescribing controlled substances.

- Inadequate pain control may result either from physicians' lack of knowledge about pain management or their misunderstanding of addiction. Fears of investigation or sanction by federal, state, and local regulatory agencies may also result in inappropriate or inadequate treatment of the pain patient.
Physicians are referred to the US Agency for Health Care Policy and Research Clinical Practice Guidelines (33) for a sound approach to the management of acute and chronic, malignant and non-malignant pain. The medical management of pain should be based on current knowledge and research and includes the use of both pharmacological and non-pharmacological modalities. Pain should be assessed and treated promptly, and the quantity and frequency of doses should be adjusted according to the intensity and duration of the pain. Physicians should recognize that tolerance and physical dependence are normal consequences of sustained use of opioid analgesics and are not synonymous with addiction. Addiction refers to both dependence on the use of substances for the drug's psychic effects and compulsive use of the drug despite consequences.

The inappropriate prescribing of controlled substances may lead to drug diversion and abuse by individuals who seek the drugs for other than legitimate medical use. Physicians must be diligent in preventing the diversion of drugs for illegitimate purposes.

The prescribing of controlled substances for pain is a legitimate medical purpose if such prescribing is (1) based on accepted scientific knowledge of pain treatment and (2) if based on sound clinical grounds. All such prescribing must be grounded in clear documentation of unrelieved pain and in compliance with applicable state or federal law.

The physician's conduct will be evaluated to a great extent by the treatment outcome, taking into account: (1) whether or not the drug used is medically and/or pharmacologically recognized to be appropriate for the diagnosis; (2) the patient's individual needs - including improvement in functioning; and (3) a recognition that some types of pain cannot be completely relieved

The Board will judge the validity of prescribing based on the physician's treatment. The goal is to control the patient's pain for its duration while effectively addressing other aspects of the patient's functioning, including physical, psychological, social and work-related factors.

A complete medical history and physical examination must be conducted and documented in the medical record. A family history should be documented with particular reference to any history of first degree relative with chemical dependence 
problems. The medical record should document the nature and intensity of the pain, current and past treatments for pain, underlying or coexisting diseases or conditions, the effect of the pain on physical and psychological function, and history of any substance abuse. The medical record also should document the presence of one or more recognized medical indication(s) for the use of a controlled substance. By definition, pain is a $s u b$ jective statement of a patient's perception of actual or potential tissue damage. The distinction between pain and suffering should be established. A patient may suffer due to pain, but may have other reasons for suffering as well. The assessment of a patient's overall condition should be made at the initial evaluation and thereafter. It is the goal of the physician to assist in the relief of suffering no matter the cause. Financial, emotional, mental, physical, and spiritual factors may contribute to the patient's suffering. Relief of the underlying reasons for suffering, as well as the pain, will lead to optimal treatment and utilization of controlled substances.

- Before beginning a regimen of controlled drugs, the physician must determine, through actual clinical trial or through patient records and history that non-addictive medication regimens have been inadequate or are unacceptable for solid clinical reasons.

- The written treatment plan should state objectives that will be used to determine treatment success, such as pain relief and improved physical and psychosocial function, and should indicate if any further diagnostic evaluations, consultations or other treatments are planned. After treatment begins, the physician should adjust drug therapy to the individual medical needs of each patient. Other treatment modalities or a rehabilitation program may be necessary depending on the etiology of the pain and the extent to which the pain is associated with physical and psychosocial impairment. The physician should discuss the risks and benefits of the use of controlled substances with the patient or his/her surrogate, including the risk of tolerance and drug dependence. If the patient is determined to be at high risk for medication abuse or has a history of substance abuse, the physician may employ the use of a written agreement between physician and patient outlining patient responsibilities, including:
1. One prescribing doctor and one designated pharmacy.

2. Urine/serum drug screening when requested.

3. No early refills and no medications called in. If medications are lost or stolen, then a police report could be required before considering additional prescriptions.

4. The reasons for which drug therapy may be discontinued such as violation of a documented doctor-patient agreement.

At reasonable intervals based on the individual circumstances of the patient, the physician should review the course of treatment and any new information about the etiology of the pain. Continuation or modification of therapy should depend on the physician's evaluation of progress toward stated treatment objectives such as reduction in patient's pain intensity and improved physical and/or psychosocial function (ie, ability to work), need of health care resources, activities of daily living, and quality of social life. If treatment goals are not being achieved despite medication adjustments, the physician should reevaluate the appropriateness of continued treatment. The physician should monitor patient compliance in medication usage and related treatment plans. The physician should be willing to refer the patient as clinically indicated for additional evaluation and in order to achieve treatment objectives. Special attention should be given to those pain patients who are at risk for misusing their medications and those whose living arrangements pose a risk for medication misuse or diversion. The management of pain in patients with a history of substance abuse or with a coexisting psychiatric disorder may require extra care, monitoring, documentation, and consultation with or referral to an expert in the management of such patients.

The physician should keep accurate and complete records, to include:

1. The medical history and physical examination;

2. Diagnostic, therapeutic, and laboratory results;

3. Evaluations and consultations;

4. Treatment objectives;

5. Discussion of risk, benefits, and limita- 


$\begin{array}{ll}\text { 6. } & \text { tion of treatments; } \\ \text { 7. } & \text { Treatments; } \\ & \text { Medications (including date, type, dos- } \\ \text { 8. } & \text { Instructions and agreements; } \\ 9 . & \text { Periodic reviews; and } \\ \text { 10. } & \text { Records should remain current and be } \\ & \text { maintained in an accessible manner and } \\ & \text { readily available for review. }\end{array}$

The results of this study, surprisingly, show that $24 \%$ of the patients were abusing opioids, half of them frequently. This was in spite of vigorous follow-up with controlledsubstance contracts, as well as other measures, including discussions during each visit, and additional interventional procedures. There were no characteristic, demographic or psychological features to identify opioid abuse, even though depression was more frequently observed in the abuse group. Thus, opiophobia appears to have justification for the interventional pain practitioner and does not appear to be as bad as some experts state. After all, it is extremely important for physicians to do no harm, neither to the patient, nor to themselves! The development and implementation of strict policies, and use of only mild-to-moderate amounts of narcotics, in conjunction with other techniques, appears to be the best way to deal with the problems of controlled substance abuse.

\section{CONCLUSION}

This study showed that there is significant abuse of opioids, with $24 \%$ of the patients abusing opioids, and frequent abuse seen in $50 \%$ of these patients, in spite of controlled substance contracts and additional relief provided by interventional techniques. Thus, it is concluded that physicians practicing interventional pain medicine must be extremely careful in administering narcotics as there are no physical, psychological or clinical characteristics to identify patients abusing the controlled substances, even though depression was more commonly seen in the abuse group. In addition, physicians must protect themselves with additional modalities of treatments, as well as strict narcotic controls and frequent random checks of abuse by their patients.

\section{REFERENCES}

1. Johnson P. The Birth of the Modern World Society. Harper Collins, New York, 1991; p 768.

2. Jamison R, Raymond S, Slawsby E et al. Opioid therapy for chronic noncancer back pain. Spine 1998;
23:2591-2600.

3. Rathmell JP, Jamison RN. Opioid therapy for chronic noncancer pain. Curr Opin Anaesthesiol 1996; 9:436442 .

4. Joranson DE. Federal and state regulations of opioids. J Pain Symptom Manage 1990; 5:333-336.

5. Turk DC, Okifuji A. What factors affect physicians' decisions to prescribe opioids for chronic noncancer pain patients. Clin J Pain 1997; 13:330-336.

6. Flor H, Fydrich T, Turk DC. Efficacy of multidisciplinary pain treatment centers: A meta-analytic review. Pain 1992; 49:221-230.

7. Manchikanti L, Pampati V, Fellows B et al. Characteristics of chronic low back pain in patients in an interventional pain management setting: A prospective evaluation. Pain 2001; 4:131-142.

8. Groer J, Brodsky M. The incidence of illicit drug use in the United States 1961-1989. Br J Addict 1992; 87:1345.

9. Regier DA, Meyers JK, Dramer et al. The NIMH epidemiologic catchment area program. Arch Gen Psychiatry 1984; 41:934.

10. Fishbain DA, Rosomoff HL, Rosomoff RS. Drug abuse, dependence, and addiction in chronic pain patients. Clin J Pain 1992; 8:77.

11. Polatin PB, Kinney RK, Gatchel RJ et al. Psychiatric illness and chronic low back pain: The mind and the spine - which goes first? Spine 1993; 18:66-71.

12. Quang-Cantagrel ND, Wallace MS, Magnuson SK. Opioid substitution to improve the effectiveness of chronic noncancer pain control: A chart review. Anesth Analg 2000; 90:933-937.

13. Moulin DE, Lezzi A, Amireh R et al. Randomized trial of oral morphine for chronic non-cancer pain. $J$ Pain Symptom Manage 1992; 7:69-77.

14. Jadad AR, Carroll D, Glynn CJ et al. Morphine responsiveness of chronic pain: Double-blind randomized crossover study with patient-controlled analgesia. Lancet 1992; 339:1367-1371.

15. McNairy SL, Maruta T, Ivnik RJ et al. Prescription medication dependence and neuropsychologic function. Pain 1984; 18:169-177.

16. Fordyce WE. Behavioral Methods for Chronic Pain and Illness. Mosby, St. Louis, 1976.

17. Maruta T, Swanson DW, Finlayson RE. Drug abuse and dependency in patients with chronic pain. Mayo Clin Proc 1979; 54:241-244.

18. Maruta T, Swanson DW. Problems with the use of oxycodone compound in patients with chronic pain. Pain 1981; 11:389-396.

19. Schofferman J. Long-term use of opioid analgesics for the treatment of chronic pain of nonmalignant origin. J Pain Symptom Manage 1993; 8:279-288.

20. Turner JA, Calsyn DA, Fordyce WE et al. Drug utilization pattern in chronic pain patients. Pain 1982; 12:357-363. 
21. Jamison RN, Anderson KO, Peeters-Asdourian C et al. Survey of opioid use in chronic nonmalignant pain patients. Reg Anesth 1994; 19:225-230.

22. Joranson DE. A new drug law for the states: An opportunity to affirm the role of opioids in cancer pain relief. J Pain Symptom Manage 1990; 5:333-336.

23. Wilson PR. Opioids and chronic pain (ed). Clin J Pain 1997; 13:1-2

24. Rush AJ, Polatin P, Gatchel RJ. Depression and chronic low back pain. Spine 2000; 25:2566-2571.

25. Fishman SM, Bandman TB, Edwards A et al. The opioid contract in the management of chronic pain. $J$ Pain Symptom Manage 1999; 18:27-37.

26. Guglielmo WJ. Can doctors put their fears to rest? Med Econ 2000; Feb 21:47-60.

27. Dahl JL. Improving the practice of pain management. JAMA 2000; 284:2785.

28. Model guidelines for the use of controlled substances in pain treatment. Presented at the March 2001 Kentucky Board of Medical Licensure Meeting. July 2001; 99:291-294.

29. Guidelines for prescribing controlled substances (Monitoring Medicine). (The prior KBML opiate guidelines.) J Ky Med Assoc 1998; 194:309-312.

30. Considerations when prescribing benzodiazepines (Monitoring Medicine). J Ky Med Assoc 1998; 96:398.

31. The stimulant regulations: 201 KAR 9:016. Restrictions on use of amphetamines and amphetamine-like anorectic controlled substances. Can also find at the KBML WebPage at www.state.ky.us/agencies/kbml.

32. The KASPER Program. See the 2000 Summer $K B M L$ Newsletter or contact The Cabinet for Health Services at 502.564.7985 or via fax at 502.564.2203.

33. Clinical Practice Guideline No. 9: Management of Cancer Pain. US Agency for Health Care Policy and Research. March 1993. AHCPR publication 94-0592. 